\title{
A FRAUDE ACADÊMICA HOJE: CAUSAS SOCIAIS E RESPOSTAS INSTITUCIONAIS ${ }^{1}$
}

\author{
Richard Epstein ${ }^{2}$ \\ Tradução de Ana Paula O. Ávila ${ }^{3}$
}

\section{Resumo}

Este artigo analisa a má-conduta em pesquisa que configura a fraude acadêmica, propondo o desenvolvimento de um desenho institucional específico e adequado para lidar com essas ocorrências. Além de conceituar a fraude a partir do seu elemento nuclear - a intenção do agente -, são estudados vários casos exemplificativos de fraude acadêmica envolvendo plágio, deliberada manipulação de dados e/ou conflitos de interesses, ocorridos em renomadas Universidades. Esses exemplos expõem os graves danos decorrentes da falta de apuração imediata face à mera suspeita de fraude. Ao final, conclui-se pela necessidade de adoção, pelas instituições de pesquisa, de procedimentos internos formais, permanentes e previamente estabelecidos para apurar e repreender a fraude acadêmica, como forma de evitar a proliferação desta prática que irradia consequências nefastas para o desenvolvimento da ciência e da sociedade.

Palavras-Chave: fraude acadêmica - plágio - falsificação de dados - processo administrativo - desenho institucional - comitê permanente para investigação de fraude - conflito de interesses.

\section{INTRODUÇÃO}

Neste artigo, devo falar de um tópico que todos nós gostarímos de varrer para debaixo do tapete se fosse possível: a integridade acadêmica e o seu oposto, a fraude acadêmica. Como uma observação inicial, fica claro que a fraude acadêmica pode ocorrer fora do ambiente da universidade, em outras instituições que conduzam pesquisas em assuntos de relevância científica. Da mesma forma, está claro que o risco de fraude acadêmica não está confinado às ciências físicas ou biológicas, mas também pode surgir em pesquisa nas ciências sociais e

\footnotetext{
${ }^{1}$ Artigo originalmente publicado em inglês pela Stanford Law \& Policy Review Vol. 21(135-154).

${ }^{2}$ Professor of Law at NYU School of Law. He has served as the Peter and Kirstin Bedford Senior Fellow at the Hoover Institution since 2000. Epstein is also the James Parker Hall Distinguished Service Professor of Law Emeritus and a senior lecturer at the University of Chicago. Member of the American Academy of Arts and Sciences since 1985 and has been a Senior Fellow of the Center for Clinical Medical Ethics at the University of Chicago Division of Biological Sciences, since 1983. E-mail: repstein@uchicago.edu

${ }^{3}$ Doutorado em Direito pela UfRGS. Professora Titular de Direito Constitucional e Direito Econômico dos Cursos de Graduação e Mestrado - UniRitter (Porto Alegre). Coordenadora do Programa de Pós-Graduação Stricto Sensu - Mestrado em Direito do UniRitter (Porto Alegre). Diretora Adjunta da Escola Superior de Advocacia da OAB/RS (2013-atual). E-mail: ana_avila@uniritter.edu.br

Revisão Técnica: Fabiana Kanan Oliveira - Bacharel em Letras pela UFRGS; Mestre em Letras pelo UniRitter - Laureate International Universities.
} 
humanidades. Entretanto, neste momento não me deterei nessas diferenças; antes, me concentrarei nos riscos fundamentais para a integridade da missão da pesquisa realizada por pesquisadores e cientistas, tanto dentro quanto fora das universidades.

A amplitude deste tópico evidencia a razão por que simplesmente mencioná-lo é, geralmente, fonte de forte desconforto e ansiedade. Não desenvolvemos protocolos e proteções institucionais para celebrar a integridade científica, que é a regra nos empreendimentos de pesquisa dentro e fora da academia. Desenvolvemos esses procedimentos de modo sistemático para lidar com o risco recorrente e com casos problemáticos de fraude acadêmica onde [e como] quer que eles apareçam. Nossa esperança é a de que a presença desses protocolos atue como um modesto obstáculo contra a perpetração dessas ações. Porém, quando medidas preventivas falham, queremos procedimentos permanentes e pré-estabelecidos para não termos que improvisar sob pressão. Felizmente, esses casos são raros, mas os riscos que eles carregam nunca devem ser minimizados. Cada incidente documentado de fraude acadêmica - e também cada alegação não comprovada de fraude acadêmica enfraquece a confiança do público e dos pares na importância do papel da pesquisa, expondo à crítica indevida pesquisadores cujo trabalho se enquadra nos padrões mais elevados de integridade científica.

Como espero demonstrar, somente uma abordagem compreensiva pode responder ao desafio que esses casos apresentam. Ao lidarmos com a fraude acadêmica, a primeira tarefa é conceitual: identificar aquelas atividades que ameaçam gravemente a missão da pesquisa e que devem ser isoladas para um tratamento especial. Em outras palavras, como exatamente se pode definir a fraude acadêmica ou científica? A segunda tarefa, de natureza repressiva, é tão importante quanto a primeira. Quais procedimentos deveriam ser utilizados para examinar os casos que se enquadram nessa definição? E quais procedimentos adicionais deveriam ser usados para identificar a extensão da fraude, uma vez que sua existência tenha sido estabelecida?

Esse é um tema no qual eu tenho alguma experiência prática. Uma das tarefas administrativas mais importantes que desempenhei na Universidade de Chicago foi liderar o Comitê de Fraude Acadêmica, em 1984, o qual, até onde sei, compilou o primeiro conjunto de regras e procedimentos sistemáticos do país para lidar com esse problema ${ }^{4}$. A fraude acadêmica é uma ocorrência relativamente rara, mas que, ao ocorrer, gera implicações aterradoras. Diversamente, conflitos de interesse são mais comuns e se disseminam por toda parte. Costumo brincar que a melhor definição para um conflito de interesse é "duas pessoas", porque quaisquer duas pessoas, quase que por definição, sempre terão interesses e objetivos divergentes.

\footnotetext{
${ }^{4}$ Para um relato do processo na época, veja Richard A. Epstein, On Drafting Rules and Procedures for Academic Fraud, 24 MINERVA 344 (1986).
} 


\section{DEFININDO A FRAUDE ACADÊMICA}

Ao lidar com os danos decorrentes da fraude acadêmica, os advogados bem sabem o que outros acadêmicos tendem a esquecer: que as ações corretivas são tão importantes [talvez até mais] quanto definir os danos subjacentes que logicamente são anteriores a elas. Começando com a primeira pergunta, a definição de fraude acadêmica não pode ser considerada tal qual um debate filosófico misterioso, despojado de consequências institucionais. Em resposta a essa pergunta, o Relatório de Fraude Acadêmica da Universidade de Chicago adotou um conceito mais restrito:

A fraude acadêmica compreende um esforço deliberado de enganar e se distingue de um erro honesto e de diferenças honestas de julgamento ou interpretação. A fraude acadêmica é definida como plágio; fabricação ou falsificação de evidências, dados ou resultados; a supressão de evidências ou dados relevantes; a má interpretação consciente de fontes; o roubo de ideias; ou a apropriação intencional e indevida do trabalho ou dos dados de pesquisa de outrem. ${ }^{5}$

Alguns postos-chave dessa definição requerem atenção. Primeiro, cumpre observar que diferentes formas de fraude acadêmica têm consequências sociais muito diferentes. Quando a fraude atinge a veracidade dos dados e das deduções retiradas dos mesmos, as consequências repercutem no próprio âmago da missão científica. Os demais membros da comunidade científica passam a trabalhar com base em informações falsas, num esforço sem fim para replicar resultados que jamais ocorreram, ou partem para novas iniciativas que jamais seriam empreendidas se a verdade fosse conhecida. A confusão começa a partir do conhecimento pressuposto, do qual outros avanços futuros dependeriam.

Diversamente, incidentes de plágio e apropriação indevida não alteram para pior a natureza do entendimento humano ou a condução da pesquisa científica, uma vez que a veracidade da informação subjacente está fora de dúvida. Ninguém quer roubar trabalhos inverossímeis ou ideias irrelevantes. Em vez disso, o que essas ações fazem é minar o sistema meritório na pesquisa, ao permitir que um indivíduo receba o crédito pelo trabalho feito por outrem. A pessoa sem mérito recebe reconhecimento, promoção e recompensas que, na verdade, pertencem a outrem.

Pode-se questionar porque esses dois tipos de má-conduta devem estar no mesmo grupo. Para tanto, existem três respostas. Primeiro, parece-me que, na verdade, os dois tipos de fraude acadêmica frequentemente andam juntos: as pessoas que fabricam dados provavelmente são as mesmas que se apropriam indevidamente do trabalho alheio. Segundo, a violação consciente dos direitos de terceiro expressa uma forma de abandono moral que requer uma forte sanção social, que é melhor administrada por um sistema unitário que possa lidar

\footnotetext{
${ }^{5}$ UNIVERSIDADE DE CHICAGO, POLICY ON ACADEMIC FRAUD $\$ 1$ (1998). Uso as definições segundo as diretrizes atuais, que seguem aquelas do original de 1984, relatório do comitê que presidi.
} vol. 08, nº. 04, Número Especial. Rio de Janeiro, 2015.pp. 2264-2286 
simultaneamente com ambos os tipos de conduta. Terceiro, os tipos de expertise necessários para lidar com ambos os problemas são suficientemente parecidos, prescindindo do desenvolvimento de procedimentos distintos para responder individualmente a cada um dos casos.

O segundo ponto do debate trata não da extensão dos casos de fraude acadêmica, mas dos tipos de máconduta que caem dentro desse escopo. Quanto a essa questão, é importante ressaltar que a definição proposta refere-se à "fraude acadêmica" em sentido estrito, e não a qualquer noção genérica de má-conduta acadêmica ou científica que poderia ocultar uma multiplicidade de pecados. Observe-se que, na definição proposta, definiu-se a fraude acadêmica em oposição aos erros honestamente cometidos e a variações honestas de julgamento ou interpretação, que, obviamente, são a sua antítese. A real tipologia de condutas é algo mais complexo, em virtude de todos os estados da mente intermediários que podem, em princípio, ser relevantes à investigação.

[Observação do Tradutor: Aqui parece apropriada a distinção entre dolo e culpa adotada no direito brasileiro, para esclarecer que, na concepção do autor, somente a modalidade dolosa (incluindo o dolo eventual) pertence à definição de fraude acadêmica proposta neste artigo. Ficam, assim, excluídas do tipo "fraude" as modalidades estritamente culposas de conduta imprudência, negligência ou imperícia, e também a culpa grave -, bem como aquilo que ele refere como erros honestos ou divergência interpretativa honesta, enquadrados ou não na noção de culpa]

Nesse sentido, releva examinar a definição de fraude acadêmica à luz do sistema de classificação de estados mentais que se usa, por exemplo, para organizar as regras dos ilícitos civis. Esta investigação começa com ilícitos intencionais [N.T.: dolo] - a fabricação deliberada ou omissão de dados. Então ela avança para o dolo eventual - a preparação dos dados sem saber ou se importar se eles são verdadeiros ou falsos [recklessness]. Ambos estados mentais se confundem por causa da atitude mental explícita que os indivíduos adotam em face da verdade ou da falsidade.

É instrutivo observar casos de reparação cível que lidam com ações fraudulentas, nas quais seja possível vislumbrar a ocorrência dessa exata equivalência. A definição-padrão de fraude requer que um reclamante prove que o réu fez conscientemente declarações falsas de fatos nos quais o reclamante confiou, sofrendo um prejuízo. $\mathrm{O}$ problema chave em definir essa ação como fraudulenta lida com o elemento mental na sua causa. No leading-case anglo-saxão Derry v. Peek (que envolvia um processo por fraude em razão de declarações errôneas veiculadas em material impresso), pelo standard de responsabilidade aplicado ao caso reconheceu-se a ocorrência fraude, a qual "fica demonstrada quando uma representação falsa foi feita (1) conscientemente, ou (2), sem acreditar na sua verdade, ou (3) de modo temerário e descuidado em relação à sua verdade ou falsidade". ${ }^{6}$ O propósito desse exercício é justamente rejeitar a noção de que a negligência comum [ordinary negligence ${ }^{7}$ ] deve ser considerada como uma variante da fraude.

${ }^{6}$ (1889) 14 App. Cas. 337, 375 (H.L.)

${ }^{7}$ N.T.: Expressão equivalente à culpa em nosso sistema jurídico. 
Aquela definição restritiva anteriormente exposta encaminha a questão, no direito moderno, para dois outros contextos significativos. O primeiro deles é o moderno sistema regulatório de valores mobiliários, em que a Suprema Corte, no caso Ernst \& Ernst v. Hochfelder, adotou exatamente essa abordagem ao se negar a equiparar a negligência à fraude. ${ }^{8}$ Embora a definição precisa de dolo eventual tenha sido deixada em aberto em Ernst \& Ernst, instâncias inferiores não hesitam em preencher esta lacuna ao declarar, de modo uniforme, que a fraude abrange o dolo eventual e não a negligência. ${ }^{9} \mathrm{O}$ mesmo entendimento se aplica às ações de difamação ajuizadas por agentes públicos e figuras públicas, nas quais o padrão de má-fé envolve uma desconsideração temerária da verdade [n.t: dolo eventual], mas não envolve qualquer tipo de negligência. ${ }^{10}$

Entretanto, a maioria das Cortes não está preparadas para ir além dessa equivalência. Desta forma, é virtualmente impossível sustentar que a culpa grave [gross negligence] - configurada no desvio crasso do protocolo-padrão de pesquisa sem qualquer intenção ou desejo de obter resultados falsos - deveria ser classificada como uma espécie de fraude acadêmica. Apesar da culpa grave fornecer evidência de comportamento impudente, estritamente falando a culpa grave jamais deveria ser confundida com fraude acadêmica. Antes, a culpa grave está mais próxima da culpa própria, ou mesmo da intenção de ter o cuidado ordinário ao se executar protocolos de pesquisa. Infelizmente, sempre existe muita negligência, e tudo isso acarreta consequências nocivas. Mas a mácula da intenção pessoal do agente está ausente, o que diminui a gravidade moral da fraude, diluindo a culpa em algum padrão genérico [amorphous] de má-conduta acadêmica ou científica. Além disso, releva lembrar que resultados simplesmente equivocados fazem parte da rotina na ciência. Incentiva-se mesmo a especulação científica que possa virtualmente dar errado, pois isso faz com que os pesquisadores corram riscos que podem levar a avanços cruciais em suas áreas. As investigações formais que revelam apenas equívocos honestos não são apenas insensatas; elas são de fato contraproducentes.

Portanto, a questão difícil é se há alguma explicação teórica que possa explicar porque se deve separar o dolo eventual da culpa grave. No fundo, penso que a intuição moral tem o seguinte fundamento utilitarista: nós condenamos a fraude acadêmica porque as pessoas que a cometem estão, na verdade, desperdiçando recursos reais para tornar as comunidades acadêmicas e científicas piores do que deveriam ser. Isso é bem diferente de qualquer forma de culpa, em que o erro está no fracasso em utilizar recursos suficientes para tornar a pesquisa científica melhor do que era. A culpa grave é uma evidência de negligência, admissível como tal. No máximo, sustenta uma suspeita de dolo eventual. Mas não configura um caso prima facie de dolo, nem mesmo permite que o descobridor do fato identifique o dolo, a menos que o desvio seja tão contundente que nenhuma explicação de

\footnotetext{
${ }^{8} 425$ U.S. 185,199 (1976).

${ }^{9}$ Cf., por exemplo, Ottmann v. Hanger Orthopedic Group, Inc., 353 F.3d 338 (4th Cir. 2003).

${ }^{10}$ Cf. New York Times v. Sullivan, 376 U.S. 274 (1964).
} 
inocência seja possível. A questão pode parecer pequena, mas as coisas frequentemente ficam confusas no calor das disputas reais. Portanto, é melhor manter as linhas conceituais bem claras antecipadamente.

Do que foi dito até aqui, está claro o que deveria acontecer no extremo oposto do espectro. Ironicamente, provas conclusivas de simples culpa por parte de um pesquisador normalmente são suficientes para dissipar qualquer suspeita de fraude acadêmica. Tudo isso não é para isentar a culpa grave ou mesmo a culpa ordinária. Existem sanções informais suficientes para lidar com a parte da negligência, sem suscitar o pesado fardo de um processo por fraude que poderia, uma vez levado a cabo, resultar não somente em destituição da posição ocupada, mas na quase certa excomunhão da comunidade de pesquisa. Para impor sanções tão severas, uma instituição dever estar muito confiante dos fundamentos da ofensa acadêmica. Ao refletir sobre a posição que tomamos em 1984, e que restou confirmada pelo Comitê Gamwell, que analisou a matéria em 1996, ela parece ainda estar correta.

\section{MEDIDAS CORRETIVAS PARA LIDAR COM A FRAUDE ACADÊMICA: O IMPERATIVO DOS PROCEDIMENTOS FORMAIS}

Uma vez delimitada a definição de fraude acadêmica, a próxima pergunta é o que deveria ser feito para tratar das medidas corretivas a esse problema em particular? E essa é a questão mais importante. Essa relevância fica evidente na controvérsia que agitou as revelações de manipulação de diversos dados na Unidade de Pesquisa Climática na East Anglia University, no Reino Unido, onde, ao que parece, não existem procedimentos previamente estabelecidos para investigar o que parece ser, desde o princípio, uma fraude abrangente e sistemática em um dos temas mais sensíveis do nosso tempo - o aquecimento global. Tal controvérsia demonstra uma falta de discernimento alarmante. Mesmo em casos bem menos graves do que esse, é descabido tolerar arranjos informais ou confortáveis, pelos quais se permite a participação, na avaliação do caso, de amigos ou associados dos cientistas sob investigação. Deve haver procedimentos institucionais previamente estabelecidos para examinar qualquer questão tão grandiosa e complicada quanto o incidente da Pesquisa Climática, pouco importando qual seja veredito científico final quanto à existência da suposta fraude acadêmica.

Desenvolver os procedimentos adequados foi a questão central que enfrentamos em 1984 na Universidade de Chicago. Naquela época, havia um sentimento favorável à adoção de procedimentos informais, geralmente confinados nos próprios departamentos ou setores institucionais, como se isso fosse a abordagem apropriada para uma investigação que tenha por objeto a fraude acadêmica. Minhas considerações particulares, que ao final prevaleceram, insistiam em procedimentos muito mais duráveis e complexos. Em particular, no intuito de evitar qualquer risco à necessária imparcialidade, a designação dos indivíduos que conduzem a investigação deve recair sobre pessoas que não pertençam ao mesmo departamento, nem à mesma disciplina, da 
pessoa acusada. Com este escopo, foi criado um comitê permanente de eminentes estudiosos, cuja tarefa era nomear o comitê de especialistas da área que assumiria o controle da investigação inicial. ${ }^{11}$ Uma vez que essa etapa estivesse completa, o Comitê Permanente fiscalizaria o trabalho desenvolvido por meio de um sistema de recursos que dava poder ao Comitê para revisar os standards legais aplicáveis que foram utilizados na audiência e para desconsiderar qualquer descoberta que fosse claramente classificada como errônea.

A primeira parte desse procedimento remonta a alguns procedimentos para a escolha dos membros do Tribunal do Júri na antiga Inglaterra, através dos quais um júri selecionaria um segundo júri, cujos membros selecionariam um terceiro júri, que por fim ouviria o caso. O critério implícito que fundamenta esta prática é imperativo da proteção contra o risco de influência indevida. A segunda parte do procedimento coloca o Comitê num papel diferente, que lida com o reexame em sede de recurso no caso em questão, dando continuidade às decisões e práticas que orientam essa área. Ao transformarmos essas práticas em um procedimento formal, surgiu a pergunta se deveríamos permitir a atuação de advogados nesses procedimentos. Chegamos a uma solução consensual que parece ter funcionado bem na prática: qualquer indivíduo acusado de fraude acadêmica tem a opção de trazer um advogado consigo para a reunião. ${ }^{12}$ Mas se esta opção for utilizada, então a Universidade também apresentará seu próprio advogado. No entanto, se a pessoa acusada abdica da presença do advogado, a Universidade também dispensará o seu. Na prática, o resultado mais frequente é que os indivíduos acusados consultam o advogado antes da audiência, mas não chegam trazê-lo para a reunião. Não tenho conhecimento de nenhuma reclamação em relação a esse resultado e acredito que outros seriam bem aconselhados a segui-lo.

Muitas pessoas perguntam por que é necessário introduzir toda essa formalidade extra para uma instituição de ensino. Existe uma resposta: procedimentos formais são necessários principalmente em razão das evidências históricas, como por exemplo, do que acontece quando a formalidade é desconsiderada. Em 1981, anos antes da formação do nosso comitê para desenvolver regras para a apuração da fraude acadêmica, o New York Times Magazine publicou um artigo de Morton Hunt, intitulado A Fraude que Abalou o Mundo da Ciência. ${ }^{13}$ Me considero muito em dívida com Hunt, por ter relatado em sua crônica o que acontece quando aquelas garantias não estão presentes. Sua vívida narrativa deixou uma marca na minha mente do quanto as pequenas fraudes - se é que essa expressão pode ser de todo apropriada - podem levar às mais desastrosas consequências, quando se dispõe somente de procedimentos ad hoc e desleixados para lidar com acusações sérias que surgem dos lugares mais improváveis. O relato de Hunt revela um conjunto incrível de amizades antigas e relações de poder que, se deixadas sem nenhuma interferência, teriam resultado em grandes constrangimentos para instituições de primeira-classe. Contudo essas consequências podem ser evitadas quando se estabelece uma

\footnotetext{
${ }^{11}$ Universidade de Chicago, supra nota 2, $\$ 2$.

${ }^{12}$ Id. $\$ 4(\mathrm{~b})(2)$.

13 Morton Hunt, A Fraud That Shook The World of Science, N.Y.TIMES MAG., Nov.1,1981, disponível em http://www.nytimes.com/1981/1 1/OI/magazinefa-fraud-that-shook-the- world-of-science.html?\&pagewanted=print.
} vol. 08, n. 04, Número Especial. Rio de Janeiro, 2015.pp. 2264-2286 
firme resposta institucional que entra em ação ao primeiro indício de fraude. Nosso comitê concluiu que o princípio básico era retirar imediatamente todo o poder das mãos de qualquer pessoa vinculada aos acusados de fraude, incluindo supervisores, colegas e coautores. Para alcançar esse objetivo, nossos procedimentos em Chicago implicam um dever, por parte de qualquer membro que tome conhecimento de fraude, de encaminhar a questão para o reitor ou dirigente adequado ou, se necessário, ao Provost ${ }^{14}$, que poderá presidir uma breve investigação para determinar se existe razão para acreditar que tal fraude possa ter sido cometida. Além disso, esse dirigente pode buscar aconselhamento com as pessoas da administração de pesquisa ou com o Comitê Permanente sobre como proceder. Nossa posição era a de que ninguém deveria ser forçado a navegar por essas águas traiçoeiras sozinho. Porém, sempre que existir razão, qualquer razão, para acreditar que alguma fraude possa ter sido cometida, esse administrador tem o dever de encaminhar o assunto para o Comitê Permanente.

Essa investigação preliminar envolve um balanço delicado de considerações, pois nenhuma investigação dessa magnitude deve ser tratada levianamente. Do mesmo modo, o agente inicial não deve fazer nenhum julgamento de culpa ou inocência. No jargão da lei criminal, esta investigação limita-se a determinar se existe qualquer evidência que justifique futura investigação. É aqui que está o maior perigo. Se o reclamante e os agentes do fronte decidem liquidar a investigação, os procedimentos formais não podem agir. Portanto, a importância de seguir o protocolo deve ser praticada desde o início.

Neste sentido, é importante lutar contra as inclinações naturais. A maioria dos cientistas de bancada não pondera exaustivamente sobre aquela proposição que qualquer operador do direito entende: que ninguém deve ser juiz em causa própria. Em vez disso, os cientistas frequentemente trabalham sob a orientação de que, enquanto pessoas dotadas de bom senso, podem resolver o problema sozinhos. Seus superiores, que desaprovam essas audiências, podem estimulá-los a tomar o caminho informal. Mas isso é um grande erro. Os cientistas e pesquisadores não são capazes de navegar por essas águas perigosas sem firmes guias de navegação. Eles são grandes tolos por pensar que seus intelectos os protegem contra sua parcialidade. Uma razão por si só suficiente para desqualificar qualquer pessoa próxima da posição de julgar, é ela ser ingênua o suficiente para pensar que está à altura da tarefa. Cientistas e pesquisadores mais espertos irão, voluntariamente, cair fora de uma responsabilidade direta ao primeiro sinal de problema. São os seus colegas menos ponderados que devem ser levados porta afora antes que seja tarde demais. Esse procedimentos têm que começar corretamente para que terminem corretamente. Sem exceções.

\footnotetext{
${ }^{14}$ Universidade de Chicago, nota supra 2, \$3(A). N.T.: O "Provost" funciona como superintendente acadêmico da Universidade de Chicago, zelando pelo adequado desenvolvimento da produção intelectual dentro dos mais rigorosos padrões científicos.
} vol. 08, n. 04, Número Especial. Rio de Janeiro, 2015.pp. 2264-2286 


\section{EXEMPLOS DE FRAUDE ACADÊMICA}

\section{A. A Fraude Soman}

Esta conclusão parece impossível se você acompanhar o relato de Hunt no New York Times, o qual relatarei em mínimos detalhes. Este caso começa de maneira simples. A Dra. Helena Wachslicht-Rodbard era uma pesquisadora júnior em endocrinologia, no Instituto Nacional de Saúde. Seu trabalho se aprofundava no estudo da anorexia nervosa, uma condição que pode levar à morte, na qual (tipicamente) mulheres sofrem uma perda de peso radical por causa de uma aversão anormal por comida. Em casos extremos, essas mulheres podem literalmente morrer de fome. $\mathrm{Na}$ grande maioria das vezes, uma intervenção clínica incisiva é necessária. Wachslicht-Rodbard, relata Hunt, havia descoberto por meio de alguns experimentos que um sinal da progressão da anorexia era o modo como as células sanguíneas das pacientes anoréxicas tendiam a se ligar mais frequentemente à insulina do que nas pessoas sem anorexia. Portanto, rastrear a redução nessa ligação dava uma medida aproximada do progresso na direção da cura. Wachslicht-Rodbard submeteu um artigo que continha essas descobertas chamado Receptores de Insulina na Anorexia Nervosa, juntamente com um simples modelo matemático para analisar o impacto desses receptores, ao New England Journal of Medicine (NEJM), em novembro de 1978.

Como é comum em ciência, todas as submissões razoáveis são enviadas para uma avaliação feita por especialistas na área. Ninguém duvida que o parecer desses especialistas é uma ferramenta que faz com que a ciência funcione. Sem eles, não há trabalho de revisado por pares. Mas, infelizmente, expertise e rivalidade com frequência aparecem juntos em uma única embalagem. Os pareceristas que são requisitados para revisar artigos frequentemente estão trabalhando na mesma área. Inclusive, frequentemente estão trabalhando no mesmo tópico, muitas vezes competindo um com o outro. É um fato brutal da vida acadêmica que, para a promoção na pesquisa, as ciências dependam da publicação de trabalhos suficientemente originais. Precedência importa para a academia tanto quanto para a lei das patentes.

Essas forças competitivas determinaram o curso dos acontecimentos narrados por Hunt. O Dr. Arnold Relman, então editor-chefe do NEJM, enviou o artigo para ser revisado por três leitores, um dos quais era o Dr. Philip Felig, que, aos 43 anos de idade, era a estrela ascendente da endocrinologia na Yale Medical School. Diferentemente dos professores de direito que tendem a ser lobos solitários, médicos pesquisadores frequentemente trabalham em grupos ou equipes, nas quais o pesquisador-sênior supervisiona o trabalho dos pesquisadores-júnior, aspirantes dentro do mesmo campo. Essa relação lhes permite alavancar sua expertise em múltiplos projetos. Ao mesmo tempo, isso faz com que caiam na tentação de se dedicar a mais projetos do que possam dar conta. Nesse caso, Felig delegou sua revisão do artigo de Wachslicht-Rodbard para um de seus 
pesquisadores júnior, Dr. Vijay Soman, cuja pesquisa promissora na Índia tinha garantido para ele um lugar cobiçado nos laboratórios de Felig. Soman escreveu um relatório negativo, recomendando uma rejeição do artigo, o qual Felig encaminhou para o NEJM depois de uma revisão superficial. Felig sabia, obviamente, que Soman estava trabalhando no mesmo projeto, mas não adotou a precaução óbvia, que seria designar a revisão do artigo de Wachslicht-Rodbard para outra pessoa do seu laboratório. Nem mesmo Felig percebeu um sinal de alerta quando a recomendação de Soman voltou com uma rejeição. É sempre fácil fazer vista grossa ao que parece ser um pequeno conflito de interesses.

Entretanto, as duas outras revisões do artigo de Wachslicht-Rodbard, retornaram mais favoráveis; então, Relman adotou a medida sensata de pedir que a autora revisasse o trabalho e o submetesse novamente. Enquanto ela fazia suas alterações, o processo de revisão trabalhou ao contrário. Soman e Felig submeteram seu artigo para o American Journal of Medicine. E dessa vez, a chamada editorial foi para o Dr. Jesse Roth, que chefiava o Laboratório de Pesquisa em Diabetes, no qual a Dr. Wachslicht-Rodbard trabalhava. Roth era um amigo de infância de Felig. Seguindo uma prática padrão, ele delegou a responsabilidade da revisão inicial do artigo de Felig para Wachslicht-Rodbard, que ficou "perplexa", segundo o relato de Hunt, ao descobrir que aproximadamente sessenta palavras do seu artigo tinham sido incorporadas ao dele, junto com o seu modelo matemático. ${ }^{15}$

Dentro dos parâmetros da Universidade de Chicago, uma descoberta como a feita por WachslichtRodbard certamente significaria um sinal estrondoso que deveria desencadear uma investigação em grande escala. Mas, nesse caso particular, aqueles procedimentos formais não estavam em ação. Assim, as acusações ameaçadoras de plágio e apropriação indébita de Wachslicht-Rodbard não tiveram o efeito que teriam tido em procedimentos formais. É impossível saber o quanto a amizade desempenhou um papel na falta de ação, mas, de qualquer modo, a primeira oportunidade de tratar do problema utilizando os procedimentos formais foi irrecuperavelmente perdida.

É importante notar que ninguém no laboratório de Roth tinha feito algo de errado. O procedimento correto prescreve que o assunto deveria ter sido encaminhado para alguém em Yale que não estivesse envolvido no processo. As pessoas prováveis eram o Dr. Samuel Thier, que era o Presidente do Departamento de Medicina de Yale, ou o Dr. Robert Berliner, que era o Diretor da Faculdade de Medicina de Yale. Qualquer um dos dois poderia ter encaminhado o assunto para um comitê permanente, isso é, se houvesse um. Mas como não havia nenhum comitê instituído, Berliner deveria ter confiado a revisão à alguém que não estivesse envolvido no incidente, com o intuito de criar alguma medida de separação entre o investigador e as partes investigadas.

Nesse caso, os eventos subsequentes confirmaram a sensatez dessa perspectiva. A Dra. WachslichtRodbard fez o que Jesse Roth não faria. Ela escreveu para o diretor Berliner, exigindo uma auditoria médica. Mas

\footnotetext{
${ }^{15}$ Hunt, Morton. Cf. nota xiii supra
} 
ele fez exatamente a coisa errada: ele encaminhou o problema para a pessoa errada e pediu um relatório ao próprio Felig. Este repetiu exatamente o mesmo erro: pediu a Soman para examinar a alegação de fraude e fazer um relatório sobre o assunto. Conforme o relato de Hunt:

Soman deu a ele uma lista de nomes de pacientes e datas (mas não suas fichas médicas do hospital), mais planilhas de dados exibindo números que, ele disse, eram médias compiladas a partir do estudo do sangue de seis pacientes. Felig não procurou nada além disso; ele disse ao reitor Berliner que o trabalho tinha sido feito de acordo com essa descrição, e Berliner escreveu à Dra. Wachslicht-Rodbard, "não existe dúvida de que os estudos de Soman e Felig foram feitos da maneira descrita no manuscrito", acrescentando que ele esperava que ela agora considerasse $o$ assunto encerrado. ${ }^{16}$

É difícil de imaginar um conjunto de reações mais estúpido para uma investigação urgente. Felig varreu todas as evidências de plágio e apropriação indevida para debaixo do tapete. Até uma pessoa que não fosse um cientista poderia se dar conta de que alguém deveria verificar os dados originais, e este alguém não deveria ser o co-autor do artigo cuja veracidade e integridade estavam sendo questionadas. Mas os procedimentos vagos tornaram essa saída fácil demais. Wachslicht-Rodbard novamente expressou seu ultraje e ameaçou "denunciar" ambos Felig e Soman, se eles apresentassem seus dados no encontro que ocorreria na American Federal of Clinical Research, que estava marcado para maio. ${ }^{17}$ Esse tumulto desencadeou outra resposta ad hoc, através da qual Felig e Roth decidiram designar um auditor externo para dar uma nova olhada nas evidências. Essa resposta ad hoc representou um (pequeno) avanço, porque ela quebrou a natureza seletiva da investigação, ainda que apenas levemente. As regras fundamentais para a investigação eram absolutamente sem forma, como o acordo inicial entre amigos não mostrava quem tinha sido escolhido, ou explicar porque uma única pessoa fora escolhida, quando a auditoria deveria ser feita e como os resultados deveriam ter sido reportados. Foi tudo irremediavelmente ad hoc.

Ad hoc, contudo, tem sua utilidade quando a vontade é apenas postergar as coisas. Porém, parecia nunca haver o momento adequando para que a auditoria ocorresse nos meses subsequentes. (É interessante observar que Hunt não revela o nome do auditor selecionado, o que já diz tudo sobre o quão independente essa pessoa era, e o silêncio com frequência alerta os sentidos para que algo possa estar errado.) Logo depois, talvez por frustração, Wachslicht-Rodbard renunciou ao trabalho de pesquisa para fazer residência. Num mundo sem supervisão formal, o desaparecimento do sujeito questionador poderia facilmente ser mal-interpretado, parecendo que o problema tinha se resolvido sozinho. Esta deve ter sido a conclusão de Felig e Soman, que, com um péssimo discernimento, publicaram seu artigo juntos em janeiro de 1980, mesmo tendo Felig concordado com um entendimento informal de que o seu artigo esperaria até que o artigo de Wachslicht-Rodbard fosse publicado.

A partir daí os problemas só se agravaram. Assim que aconteceu a publicação, Felig estava sendo

${ }^{16} \mathrm{Id}$. 
considerado para o cargo de Presidente do Departamento de Medicina da Columbia's Physicians and Surgeons $(P \& S)$. Infelizmente, Felig tropeçou em outra norma institucional, a qual prescreve que os indivíduos que têm esqueletos no armário devem revelá-los para seus potenciais empregadores como parte do exame de vida pregressa. Felig não revelou qualquer informação sobre a investigação para o comitê de investigação na P\&S. Em vez disso, ele recomendou Soman para assumir um cargo de Professor Assistente no Departamento de Medicina assim que Felig assumisse seu novo posto de comando.

Para entender a enormidade do problema, é importante estabelecer o contexto institucional. Enquanto os advogados estão acostumados com instituições em menor escala, um departamento de medicina típico é uma estrutura imensa que pode ter uma dúzia de setores e mais de quinhentos médicos num ritmo frenético de compromissos acadêmicos. Então, imagine-se a velha metáfora política: o Presidente de Medicina pode não ser o Rei da França, mas certamente é o Duque de Borgonha, com plenos poderes em seu domínio. As conexões diplomáticas são amplas e decorativas; as recompensas pelo sucesso são enormes e as armadilhas estão por todos os lados.

Neste ponto da narrativa, as duas questões - o cargo na P\&S e o incidente do artigo de Felig/Soman - se fundiram em uma. Wachslicht-Rodbard viu a publicação e ligou para Roth com uma fúria de arrepiar. Roth deu-se conta de que o problema não poderia mais ser contido, e, assim, ligou para Felig - outra atitude equivocada - para marcar outra auditoria independente. Dessa vez, o homem certo foi selecionado: o Dr. Jeffrey Flier, então diretor da Harvard Medical School. Flier prontamente conduziu a auditoria e desvendar a fraude foi como tirar doce de criança. Flier pediu para Soman exibir os dados brutos, fornecer os nomes dos pacientes e explicar porque todos os dados estavam alinhados de trás para a frente. Como demonstrou-se ser o caso, um dos pacientes no estudo estava faltando, e não havia qualquer gráfico dos dados originais. Flier rapidamente deu-se conta de que os dados formavam uma curva que não se ajustava com a teoria. Após três horas a investigação estava encerrada e Soman confessou a fraude. Claramente, nesse tipo de situação, as questões definidoras em torno da fraude acadêmica não estavam em ação; antes, as estruturas institucionais eram o que realmente importava. A cultura interna de conveniência e a resistência à influência externa é que mantiveram as coisas engavetadas pelo período em que estiveram.

O colapso no sistema teve muitas consequência colaterais. Duas são dignas de menção. A primeira é o que deveria ter acontecido quando ficou entendido que Soman havia cometido uma fraude no artigo de sua pesquisa. Sob as diretrizes estabelecidas pela Universidade de Chicago, teria sido necessário designar uma segunda comissão para investigar a extensão da fraude. ${ }^{18}$ Entretanto, esse não é um exercício trivial, especialmente na

${ }^{18}$ UNIVERSIDADE DE CHICAGO, POLICY ON ACADEMIC FRAUD, \$5(A). 
comunidade médica. Os médicos são prolíficos. Pequenos avanços podem gerar vários documentos e avanços maiores podem gerar dezenas mais. A maior parte da pesquisa médica conta com o trabalho em equipe; dessa forma, quatro ou cinco médicos ou cientistas colaboram para um dado artigo. Às vezes cada pessoa escreve a sua parte, com pouco conhecimento do que foi escrito pelos autores responsáveis pela redação das outras partes. Algumas vezes, o trabalho é mais genuinamente colaborativo. Em outros casos, o cientista-sênior supervisiona o trabalho de um cientista-júnior. Deste modo, a tarefa de determinar a extensão dos efeitos da fraude equipara-se a uma busca sob os escombros e implicaria ler dezenas de documentos. Se nenhuma fraude for encontrada, muito melhor assim. Mas, se equívocos graves forem encontrados, suscitam-se questões graves e confusas: Havia fraude nesse caso ou em algum outro? Sendo a resposta positiva, quais das muitas pessoas nos artigos com coautoria deveriam ser implicadas? Se essas pessoas pertencem a outras instituições, quem então deveria conduzir a investigação? Será que os artigos deveriam ser recolhidos, no todo ou em parte, porque a autoria de uma pessoa macula o resto? Outros pesquisadores devem confiar nos dados desses artigos recolhidos? Devido à prevalência de múltipla autoria na área médica, o processo todo pode ser longo e complexo.

A falta de protocolos institucionais também criou uma série de consequências colaterais quando o processo de nomeação de Felig para Presidente da Medicina na P\&S seguiu seu rumo. Depois que Flier descobriu a fraude de Soman, a conduta de Felig tornou-se extremamente difíil de ser defendida. Se delegar a revisão do artigo para Soman já foi imprudente, a falta de revisão do relatório negativo foi ainda mais grave. A decisão de publicar antes que o assunto estivesse resolvido foi precipitada e imponderada. A decisão de ele mesmo conduzir a investigação de Soman foi imperdoável. Sua decisão de permanecer calado durante o processo de entrevista na Columbia foi menos que sincera. Quando a Universidade de Columbia passou pela trabalhosa reavaliação da nomeação, Felig foi forçado a renunciar. Mesmo que as ações de Felig não correspondessem à fraude acadêmica, a grave negligência em supervisão não é uma qualificação para um cargo acadêmico importante. Depois disso, com alguma relutância, Felig foi aceito de volta em Yale, mas destituído do cargo de chefia. Deixo para que os outros decidam se a lealdade entre colegas foi suficiente para garantir esse resultado. Entretanto, no fim das contas, fica claro que a falha nos mecanismos para lidar adequadamente com a fraude acadêmica tem vastas implicações institucionais.

\section{B. A Fraude Darsee}

Enquanto eu me preparava para o trabalho no Comitê de Fraude Acadêmica em 1984, me deparei com outra fraude menos dramática que a de Soman, mas, ainda assim, dramática por suas implicações. Dessa vez a fraude envolvia um jovem cientista pesquisador, o Dr. John Darsee, que tinha ido para a Harvard depois de alguns 
anos na Emory. ${ }^{19}$ As mesmas patologias do caso Soman também aconteceram nessa segunda fraude. Darsee era uma estrela na cardiologia, mas um incidente de fraude resultou na sua queda. Em maio de 1981, Darsee foi pego adulterando datas nos seus relatórios, para fazer com que estudos que tinham levado apenas algumas horas parecessem ter sido feitos ao longo de várias semanas. Nenhuma revisão formal foi feita nessa fabricação óbvia. Em vez disso, o assunto foi encaminhado para o Dr. Eugene Braunwald, chefe da cardiologia e também um distinto pesquisador ele próprio, que deu fim à associação acadêmica de Darsee, mas aceitou a defesa de que este seria um incidente isolado. Não houve comitê independente em ação e nenhum relatório foi encaminhado ao National Institutes of Health $(\mathrm{NIH})$, que poderia ter conduzido um trabalho próprio de investigação. Em vez disso, Braunwald e o diretor de seu laboratório, Robert Kloner, levaram o assunto ao Reitor Daniel Tosteson, que deixou o problema seguir seu curso natural. Braunwald e Kloner revisaram o incidente, mas não encontraram qualquer outra evidência de fraude.

Acontece que eles estavam equivocados. Darsee era reincidente. Anos atrás quando revisei os arquivos, fiquei impressionado com o que pareceu ser literalmente dezenas de artigos que tiveram que ser recolhidos pelos coautores-sênior de Darsee. Um estudo inteiro do NIH foi arruinado, e Harvard ressarciu o valor da bolsa, como se isso fizesse alguma diferença. Para o nosso propósito, a lição principal é clara: procedimentos informais por pessoas despreparadas não darão conta do recado. O corpo docente e os pesquisadores precisam seguir os protocolos não apenas pela proteção de suas instituições, mas também pela sua própria proteção profissional.

\section{Climategate ${ }^{20}$}

Quando comecei este artigo, a Climategate ainda não tinha se tornado um assunto sério. É claro que houve discussões intermináveis sobre o aquecimento global e as mudanças climáticas representarem uma série de ameaças à humanidade, que exigia uma ação imediata em grande escala, ou seriam um fenômeno natural que o comum dos mortais não poderia evitar com a redução da quantidade de dióxido de carbono emitidos dos canos de descarga. ${ }^{21} \mathrm{Na}$ minha opinião, a tese alarmista é menos convincente do que muitos acreditam. ${ }^{22}$ Mas as acusações de fraude nas atividades da Unidade de Controle Climático de East Anglia independem do

\footnotetext{
19 Cf. Claudia Wallis et al., Medicina: Fraude em Laboratório da Harvard, TIME, Fev. 28, 1983, disponível em http://www.time.com/time/magazinearticle/0,9171,955142,00.html.

${ }^{20}$ Nota do Tradutor.: O nome "Climategate" surgiu inicialmente nas repercussões, via twitter, do escândalo (conhecido como um dos mais graves ocorridos na comunidade científica mundial) envolvendo adulteração de dados constantes em pesquisas sobre o aquecimento global. O sufixo "gate", na língua inglesa, passou a ser utilizado para designar situações de escândalo a partir do famoso "Watergate", que derrubou o Presidente Nixon da Presidência dos Estados Unidos da América na década de 70.

${ }^{21}$ Cf. Massachusetts v. EPA, 549 U.S. 497 (2007).

${ }^{22}$ Cf. Richard A. Epstein, Dióxido de Carbono: Nosso Mais Novo Poluente, 43 SUFFOLK U. L. REv. (2010).
} vol. 08, nº. 04, Número Especial. Rio de Janeiro, 2015.pp. 2264-2286 
esclarecimento dessa questão. É suficiente que os críticos tenham expressado grave preocupação com os dados. ${ }^{23}$ Os críticos apontaram esforços para remover evidências de ambos, da Pequena Idade do Gelo e do período de aquecimento medieval. Eles também apresentaram evidências de que alguns pesquisadores selecionaram dados atuais para remover medições mais frias dos cálculos completos. A questão da fraude acadêmica é real.

Entretanto, em geral, o impacto dessa evidência científica tem pouca relevância quando se trata de fraude acadêmica. A definição de fraude acadêmica, de acordo com os procedimentos de Chicago, abrange o modo padrão de manipular dados com o intuito de esconder a verdade. Porém, não serve de defesa às acusações de fraude acadêmica demonstrar que as conclusões dos indivíduos acusados eram na verdade verdadeiras. Esse tipo de defesa lembra aquela apresentada pelo juiz Sherman Manton, do Segundo Circuito, na ocasião em que foi condenado por suborno na década de 1920. Manton alegou que ele havia recebido dinheiro somente da parte com a qual concordava por princípio. E então aqui está: disputas substanciais sobre mudanças climáticas que sejam propostas por indivíduos que adulteraram dados podem até estar corretas, mas isso não afeta em nada a investigação por fraude. A suprema relevância da uma proposta não redime a fraude cometida ao longo do caminho. Pense deste modo: a maioria das fraudes são cometidas por indivíduos que pensam que estão certos e que os dados inconvenientes é que não estão cooperando. Se ele estão mesmo certos em suas suposições, então a fraude tem uma menor probabilidade de ser descoberta, porque outros pesquisadores poderão replicar os resultados, sobre os quais os nossos fraudadores alegarão precedência. Mas apesar de tudo há fraude, e aí está.

Neste ponto, a questão passa a ser como lidar com uma investigação de fraude de grande escala como o "Climategate". De acordo com os relatórios em geral, parece que a questão passou ao largo dos rigorosos protocolos internos da universidade, sem falar nas diversas instituições que estão envolvidas. Um investigador sugerido, Philip Campbell - o editor de Nature -, renunciou depois de sofrer acusações de ter defendido os cientistas da East Anglia antes da investigação. ${ }^{24}$ Por que razão o editor-chefe de um periódico de prestígio sem qualquer expertise em ciências climáticas foi designado para o caso, talvez seja a maior fonte de preocupação. Mais preocupante ainda do que os proeminentes membros de uma comissão é o risco de que a investigação seja conduzida por pessoas políticas e não científicas, que não seguirão os protocolos previamente estabelecidos. É difícil prever como esse risco pode ser controlado, mas minha posição pessoal é a de que não haverá sossego a menos que (e até que) nós tenhamos confiança no comitê escolhido. Porém, diferentemente das fraudes comuns

\footnotetext{
${ }^{23}$ Cf., por exemplo, Marc Sheppard, IPCC: International Pack of Climate Crooks, AMER1CkN THINKER, Fev. 4, 2010, http://www.americanthinker.com/2010/02/ipcc.-intemational-paci of_cli.html; Marc Sheppard, UN Climate Reports: They Lie, AMERICAN THINKER, Out. 5, 2009, http://www.americanthinker.com/2009/10/un climate reports they lie.html. O grande maligno IPCC é o Painel Intergovernamental de Mudança Climática e uma organização que opera sob proteção das Nações Unidas.

${ }^{24}$ Climate Change Investigator Resigns over Interview Defending Researchers, TELEGRAPH, Fev. 12, 2010, available at http://www.telegraph.co.uk/earth/environiment/ climatechange/7219070/Clinate-change-investigator-resigns-over-interviewdefeding- researchers.html.
} 
em assuntos técnicos que ocorreram com Soman e Darsee, aqui as ferramentas políticas intervém, tornando realmente difícil encontrar examinadores que tenham, ao mesmo tempo, conhecimento técnico e imparcialidade. Devido à provável extensão da fraude potencial, haverá dificuldades enormes em decidir quais dados revisar, quais indivíduos terão que testemunhar, e assim por diante.

A escala das investigações nesse assunto é assustadora. Os modestos procedimentos da Universidade de Chicago não foram, e não são, desenvolvidos para lidar com uma investigação desta magnitude. Não está claro se algum conjunto de regras procedimentais internas de alguma universidade poderia estar à altura de resolver essa questão tão grave. Minha recomendação pessoal é que provavelmente seja melhor para os investigadores tornarem público todo e qualquer dado, para que qualquer um possa arriscar sua própria interpretação, que pode então ser submetida a alguma banca examinadora para revisões adicionais. Há informação pública suficiente para fazer essa abordagem parecer sensata. Mesmo sem audiências públicas formais, há um precedente neste tipo de exame [público], que levou à descoberta de anomalias nos dados, do exaustivo trabalho dos canadenses Steve McIntyre e Ross McKitrick, em particular conexão com a temperatura das superfícies, expondo os erros que a Unidade de Pesquisa Climática cometeu em suas medições da temperatura da superfície e do ar na terra. Tampouco está claro o que deveria ser feito politicamente até que a poeira tenha baixado, o que poderia levar anos. Mas a possibilidade de que a ciência fraudulenta possa ir tão longe agora está admitida. Meu conselho seria colocar todas as principais iniciativas quanto ao aquecimento global em espera, até que um consenso seja obtido quanto à interpretação dos dados. A questão aqui é de uma magnitude jamais vista, e que esperançosamente nunca mais será vista.

\section{A Fraude no Autismo e Vacinas}

Mais recentemente, a questão da fraude acadêmica surgiu novamente num contexto que afetou a vida de muitos indivíduos. Tem havido um fluxo constante de reclamações alegando que as vacinas ${ }^{25}$ deveriam ser consideradas a causa do autismo, uma doença compreensivelmente temida que pode incapacitar a vida de muitas pessoas. Mas a ciência reputada desconsidera a relação entre as vacinas e o autismo. Entretanto, uma voz aguda pode alimentar um pânico generalizado que leva vozes mais sãs para o seu lado. Este cenário não é novo. Em 1998, Andrew Wakefield e outros coautores publicaram um estudo no The Lancet, um periódico inglês de prestígio, que pretendia estabelecer uma ligação entre a vacina para o sarampo, caxumba e rubéola (SCR) - a vacina tríplice viral - e uma dupla mortal de condições perigosas: autismo regressivo e inflamação do cólon. ${ }^{26}$ Vinte anos depois

\footnotetext{
${ }^{25}$ N.T. o autor refere-se à vacina tríplice-viral.

${ }^{26}$ A.J. Wakefield et al., Ileal-Lymphoid-Nodular Hyperplasia, Non-Specific Colitis, and Pervasive Developmental Disorder in Children, 351 LANCET 637 (1998).
} 
do estudo ser publicado, houve uma retratação pelo The Lancet. ${ }^{27}$ A grande demora entre a publicação e a retratação sugere que o sistema corretivo para lidar com a fraude acadêmica está seriamente comprometido, o que quer dizer que nenhuma das instituições a que pertencem os coautores do estudo julgou conveniente conduzir um exame por conta própria, apesar da quantidade de objeções ao estudo. E o The Lancet também estava "dormindo na direção".

A longa demora fez diferença, porque ele levou a consequências [human consequences] graves para muito além do laboratório. Segundo o relato de David Gorsky, a história é quase horrível demais para ser contada. Com a publicação de seu artigo, "Wakefield conseguiu levar os índices de vacinação SCR no Reino Unido para abaixo do nível do grupo de imunidade, de $93 \%$ para $75 \%$ (e para a faixa de 50\% em algumas partes de Londres)" ${ }^{28}$ Os índices de sarampo que o Reino Unido tinha considerado como contidos em 1994 continuaram a subir, e por volta de 2008, a doença foi mais uma vez considerada "endêmica". Uma fração dos pacientes de sarampo, caxumba e rubéola morre, o que significa que nesse caso, a pesquisa fraudulenta causou mortes. Não vejo razão por que - dentro da teoria geral da responsabilidade civil - algumas vítimas não pudessem sair vitoriosas em uma ação judicial particular, ou talvez reunidas em uma ação coletiva, contra Wakefield e companhia com base no regime jurídico comumente dispensado à simulação ou dolo. A falsidade das declarações que ele fez era evidente. O declínio no índice de imunização era muito grande pare ser ignorado. As injúrias resultantes eram muito específicas para serem negadas. Existem, certamente, as dificuldades comuns com o nexo causal probabilístico, dado que o índice antecedente de qualquer doença nunca pode ser levado até zero. Mas o grande aumento em probabilidade justifica a recuperação de pelo menos alguns danos para cada perda, mesmo que algum desconto precise ser feito para a probabilidade antecedente das ocorrências naturais.

Ao examinar o caso Wakefield, percebe-se que a fraude deveria ter sido estrondosa, não fosse a ciência, conforme Gorski relata, inacreditavelmente desleixada. Nenhum cientista conceituado poderia, em qualquer momento, ter replicado os resultados, o que é uma evidência óbvia de profunda irregularidade. Além disso, o caso apresenta os piores conflitos de interesse imagináveis. Evidentemente, Wakefield tinha se inscrito para patentear uma vacina alternativa menos de um ano antes de publicar seu artigo no The Lancet. ${ }^{29}$ Ademais, valores substanciais foram pagos a Wakefield para que ele realizasse sua pesquisa para escritórios de advocacia [plaintiff law firms], a fim de utilizá-la como argumento em ações judiciais contra vários fabricantes de vacinas. ${ }^{30}$ Despiciendo dizer que nenhuma dessas conexões financeiras foi revelada ao tempo da publicação.

\footnotetext{
${ }^{27}$ Editores, Retraction-Ileal-Lymphoid-Nodular Hyperplasia, Non-Specific Colitis, and Pervasive Developmental Disorder in Children, 375 LANCET 455 (2010).

${ }^{28}$ Comentário de David Gorski to Science-Based Medicine, http://www.sciencebasedmedicine.org/, pff370 (Feb. 8, 2009).

${ }^{29}$ Para detalhes, veja Brian Deer, The Wakefield Factor, http://briandeer.com/wakefield-deer.htm (último acesso: Mar. 24, 2010).

30 Brian Deer, MMR Doctor Given Legal Aid Thousands, TIMESONLINE, Dez. 31, 2006, http://www.timesonline.co.uk/tol/news/uk/article1265373.ece.
} 
O risco de litígio ilustrado nesse caso não está confinado às vacinas SCR. Tem havido um esforço enorme para mostrar que o Timerosal, um composto de mercúrio usado para ligar múltiplas vacinas juntas em uma única dose, tem sido responsável pela causa do autismo. A resposta judicial para isso foi rejeitar esta conexão depois de uma revisão exaustiva das evidências, tanto em ações civis ${ }^{31}$ quanto em acordos envolvendo ressarcimento sem culpa [no-fault compensation] para as crianças vítimas das vacinas. ${ }^{32}$

\section{ACUSAÇÕES FALSAS DE FRAUDE ACADÊMICA}

Até aqui, a principal discussão de fraude acadêmica se concentrou em assegurar que os responsáveis por grave má-conduta estejam sujeitos às sanções necessárias. Porém, esses procedimentos também têm uma segunda função, que é resguardar o risco de que alguém faça acusações falsas de fraude acadêmica ou científica. Mais concretamente, existe o risco potencial de que colegas ressentidos possam fazer essas acusações. A adoção de procedimentos formais padronizados faz com que as pessoas pensem duas vezes antes de fazer acusações sem fundamento, porque elas sabem muito bem que o relatório que exonera a pessoa acusada poderá conter também reprimendas àquela que fez as acusações.

Qualquer decisão no sentido de evitar procedimentos formais instituídos já é um forte sinal de enorme irregularidade. Uma lição sobre o que pode dar errado quando os procedimentos estabelecidos não são seguidos, surgiu no meio do contencioso judicial envolvendo o medicamento Vioxx. A história começa em 2000, com a publicação de um artigo no New England Journal of Medicine que tratava dos riscos de complicações cardíacas e intestinais associados ao uso do Vioxx. ${ }^{33} \mathrm{O}$ artigo emitia um parecer, no geral, favorável ao Vioxx, isso antes que a Merck o retirasse do Mercado por conta de complicações cardíacas em setembro de 2004. Após a retirada do mercado, o litígio começou com toda a força contra a empresa, em grande parte centrado na publicação anterior do artigo sobre o Vioxx no NEJM.

O incidente mais dramático aconteceu em dezembro de 2005, quando o New England Journal of Medicine anunciou em seu website "uma declaração de preocupação" ["expression of concern”] na véspera do seu depoimento no litígio envolvendo o Vioxx, ajuizado por vários reclamantes contra a Merck. ${ }^{34}$ Uma "expression of

\footnotetext{
${ }^{31}$ Doe v. Ortho-Clinical Diagnostics, Inc., 440 F. Supp. 2d 465 (M.D.N.C. 2006).

${ }^{32}$ Cf. Pafford v. Sec'y of Health \&Human Servs., 451 F.3d 1352 (Fed. Cir. 2006) (en banc) (rejecting causal connection to systematic juvenile rheumatoid arthritis); veja também Ctrs. for Disease Control \& Prevention, Thimerosal in Seasonal Influenza Vaccine, http://www.cdc.gov/flu/about/qa/thinerosal.htm (último acesso: Mar. 24, 2010)

("Não existe nenhuma prova convincente de malefício causado por baixas doses de timerosal nas vacinas, exceto por reações menores como vermelhidão e inchaço no local da injeção").

${ }_{33}$ Claire Bombardier et al., Comparison of Upper Gastrointestinal Toxicity of Refecoxib and Naproxen in Patients with Rheumatoid Arthritis,343 NEW. ENG. J. MED. 1520 (2000).

${ }^{34}$ Escrevi exaustivamente em dois outros lugares sobre o que considero ser uma brecha na ética profissional no litígio do Vioxx. Veja RICHARD EPSTEIN, OVERDOSE: How EXCESSIVE REGULATION STIFLES PHARMACEUTICAL vol. 08, no. 04, Número Especial. Rio de Janeiro, 2015.pp. 2264-2286 
concern" é um modo educado de acusar a empresa de fraude acadêmica. Tanto os cientistas independentes quanto os da Merck responderam à primeira série de acusações, e também à segunda que se seguiu. ${ }^{35}$ Nessa instância, seguindo o conselho de seu relações públicas, o NEJM postou o ataque online na noite anterior ao depoimento, por conta da preocupação de que a publicação poderia parecer desleixada na supervisão editorial, pois suas revisões quanto ao artigo Vioxx original não tinham encontrado efeitos negativos sérios causados pelo uso do medicamento. ${ }^{36} \mathrm{O}$ centro da disputa dizia respeito à decisão de usar diferentes pontos de chegada em experiências clínicas relativas às questões cardíacas e intestinais. A avaliação cardíaca terminou mais cedo que a intestinal, para permitir mais tempo para avaliar os resultados, pois a avaliação é mais difícil nos casos cardíacos. Todas essas decisões foram tomadas antecipadamente e aprovadas por auditores externos. ${ }^{37}$

Porém, depois de encerrada a parte cardíaca da experiência, três eventos desfavoráveis ocorreram no grupo estudado no Vioxx (um dos quais no grupo de controle), o que teria mudado levemente os resultados. Mas, por que razão este episódio conta como fraude em vez de boa ciência é algo que nunca foi explicado. Neste particular, o ponto mais gritante foi que os editores do NEJM não seguiram os seus próprios procedimentos, que exigiam que essas fraudes fossem reenviadas para exame por suas instituições de origem. ${ }^{38}$ É claro que não havia nenhuma questão de saúde para apressar a publicação de suas conclusões dúbias porque a Merck tirou o Vioxx do mercado voluntariamente quinze meses antes. O único motivo foi comercial. E com qual propósito? Um exame comparativo recente da toxicidade do Vioxx antes dele ser retirado em 2004 e outros NSAIDs (medicamentos anti-inflamatórios não esteroides) produziram resultados de acordo com a tabela seguinte, onde o celecoxib é Celebrex e rofecoxib é Vioxx. ${ }^{39}$

INNOVATION 209-18 (2006); Richard Epstein, Conflicts of Interest in Health Care: Who Guards the Guardians?,50 PERSP. IN BIOLOGY \& MED. 72, 84-88 (2007).

${ }^{35}$ Cf. Gregory Curfman et al., Expression of Concern: Bombardier et al., "Comparison of Upper GastrointestinalToxicity of Rofecoxib and Naproxen in Patients with Rheumatoid Arthritis", 353 NEw ENG. J. MED. 2813 (2005); Gregory Curfinan et al,, Expression of Concern Reaffirmed, 354 NEW ENG. J. MED. 1193 (2006); Claire Bombardier et al., Response to Expression of Concern Regarding VIGOR Study, 354 NEw ENG. J. MED. 1196 (2006); Alise Reicin \& Deborah Shapiro, Response to Expression of Concern Regarding VIGOR Study,354NEWENG.J.MED. 1196 (2006).

${ }^{36}$ Cf. David Armstrong, Bitter Pill: How the New England Journal Missed the Warning Signs on Vioxx, WALL ST. J, May 15, 2006, at Al. É digno de nota que o título de Armstrong também se equivoca a respeito da história real.

${ }^{37}$ Para o relato completo da Merck sobre esse e outros eventos, cf. o Relatório do Honorífico John S. Martin, Jr. to the Special Comm. da diretoria da Merck \& Co. 71-80 (2006), disponível em http://www.merck.com/newsroom/vioxx/martinreporthtml.

${ }^{38}$ Cf. Int'l Comm. of Med. Journal Editors, Uniform Requirements for Manuscripts Submitted to Biomedical Journals, http://www.icmje.org/publishing..2corrections.html (último acesso, Mar. 24, 2010); O segundo tipo de dificuldade é a fraude cientifica. Se surgem dúvidas substanciais sobre a honestidade ou integridade de um trabalho, submetido ou publicado, é responsabilidade do editor garantir que a questão seja tratada de modo apropriado, normalmente pela instituição patrocinadora do autor. Ordinariamente, não é responsabilidade do editor conduzir uma investigação completa ou determinar que a responsabilidade seja da instituição onde o trabalho foi feito ou da agência patrocinadora.

39 Cf. Sue Hughes, Naproxen Best NSAID for Heart-DiseasePatients, HEARTWiRE, 28 de maio, 2009, http://www.theheart.org/article/974679.do. 


\begin{tabular}{|c|c|c|}
\hline FÁRMACO & $\begin{array}{c}\text { IRR(DOENÇA } \\
\text { CARDIOVASCULAR SÉRIA) }\end{array}$ & $\begin{array}{c}\text { IRR(DOENÇA } \\
\text { CARDIOVASCULAR } \\
\text { SÉRIA/MORTE) }\end{array}$ \\
\hline Naproxeno & 0.88 & 0.91 \\
\hline Ibuprofeno & 1.18 & 1.14 \\
\hline Diclopenac & 1.27 & 1.38 \\
\hline Celecoxib & 1.03 & 0.99 \\
\hline Rofecoxib & 1.19 & 1.07 \\
\hline
\end{tabular}

Esses resultados mostram alguma elevação para o Vioxx, mas se o Vioxx deveria ser retirado do mercado, então certamente o mesmo deveria acontecer com o ibuprofeno, uma vez que os riscos adicionais são levemente mais altos. Mas a história completa deve levar em consideração o risco gastrointestinal, e quando esses números são considerados a margem se estreita. Percebam também que os números aqui somente levam em conta os efeitos colaterais e não medem a efetividade, que é alta para muitas das pessoas que utilizam o Vioxx. Independente de como esses números são fatiados, o caso para a remoção do Vioxx parece ser, em retrospecto, muito tênue e a questão da responsabilidade, quando comparada com as alternativas, parece menor que o acordo de $\$ 4.85$ bilhões que a Merck alcançou aos litigantes. ${ }^{40} \mathrm{O}$ Vioxx permanece fora do mercado atualmente, mesmo que muitos acreditem que ele deveria ser disponibilizado para uso, ao menos nos hospitais para o controle de sangramento pós-operatório. É claro que ele permanece disponível para comercialização em muitos outros países, nos quais o seu uso contínuo não gerou nenhuma nova acusação de perigo inconveniente ou de fraude acadêmica.

\section{CONCLUSÃO}

O que, então, pode ser aprendido com esses relatos? A primeira e mais importante lição é que nenhum grupo está imune aos perigos de sucumbir à fraude acadêmica. Os perpetradores de fraudes que foram citados neste artigo eram cientistas de bancada desesperados para progredirem em suas carreiras. Havia cientistas e físicos com forte comprometimento ideológico com o aquecimento global. Havia um médico que esperava ganhar recompensas pelo registro de patentes e advogados que secretamente financiavam sua pesquisa. A omissão mais notável dessa lista de fraudadores acadêmicos diz respeito às corporações. Acredito que a explicação não está na magnitude intrínseca às corporações e seus líderes. Antes, ela se encontra no fato de que as empresas estão totalmente expostas à perda dramática de sua reputação cada vez que seus produtos funcionem mal. É só olhar para os enormes esforços feitos pela Toyota para tentar apaziguar o interesse do público sobre a qualidade de seus produtos, mesmo em um caso que não contém uma suspeita de fraude, e no qual a preocupação em relação à

\footnotetext{
${ }^{40}$ Lewis Krauskopf, Merck Agrees to Pay \$4.85 Billion in Vioxx Settlement, REUTERS, 9 de novembro, 2007, disponível em: http://www.reuters.con/article/idUSL0929726620071 110.
} 
responsabilidade é pequena se comparada aos outros custos de lidar com um recall e reconstruir uma imagem arruinada. Fraudes numa organização desse porte geram danos colaterais no mínimo tão importantes, senão mais importantes, que a responsabilidade civil e as sanções regulatórias às quais essas organizações poderiam estar expostas.

Por fim, o que deveríamos concluir com este estudo de fraude acadêmica? O ponto principal é que como todos os sistemas de controle social, deve haver um desenho institucional adequado para lidar com dois tipos de erro: a fraude acadêmica e os conflitos de interesse. Não se pode deduzir, com os instrumentos de que dispomos, se empresas comerciais são boas ou ruins. Em questões como essa, ambos cenários são possíveis. Da mesma forma, não se deve presumir que todos os acadêmicos estão livre de suspeita caso não tenham um motivo financeiro direto e imediato. Existem muitos motivos de outra natureza, desde o progresso professional à ideologia política, que poderiam alimentar várias formas de fraude acadêmica e científica. Na medida em que os incidentes aumentam, a quantidade de cuidado administrativo necessário para combater as fraudes deve também aumentar. Os valores tradicionais de neutralidade, impessoalidade e legalidade podem fazer por essa área mais do que se poderia supor. Afinal, os únicos julgamentos triviais que podemos fazer se relacionam com a qualidade dos nossos mecanismos institucionais. Acusações específicas contra grupos específicos têm que ser provadas nas questões envolvendo a integridade acadêmica, do mesmo modo que em todos os outros lugares. Aqueles que pensam que podem frustrar o trabalho árduo desenvolvido, por conta da investigação de fraude acadêmica, estão apenas enganando a si mesmos e abrindo caminho para uma quantidade de fraudes e má-conduta muito maior do que qualquer sociedade responsável deveria tolerar.

\title{
ACADEMIC FRAUD TODAY: SOCIAL CAUSES AND INSTITUTIONAL ANSWERS
}

\begin{abstract}
This article analyses academic or scientific misconduct that should be regarded as academic fraud, proposing a specific institutional design to properly respond to it. It presents a definition for academic fraud exploring its core element - the agent's intention -, and studies a number of examples of fraud that took place in renowed institutions, concerning plagiarism, careless or deliberate adulteration of data, and/or conflicts of interests. These examples expose the damage suffered when suspected academic fraud is not reported from the very beginning. At the end, the author concludes for the urgent need to establish formal procedures and standard protocols within universities and other research institutions to inquire and repress academic fraud, in order to avoid the proliferation of its consequences and shattering implications for the development of science and society.
\end{abstract}

Keywords: academic fraud - plagiarism - data falsification - internal procedure - institutional design - standing committee for fraud inquiry - conflict of interests. 


\section{REFERÊNCIAS BIBLIOGRÁFICAS}

ARMOSTRONG, David Armstrong. Bitter Pill: How the New England Journal Missed the Warning Signs on Vioxx, WALL ST. J., May 15, 2006.

BOMBARDIER, Claire, et al., Comparison of Upper Gastrointestinal Toxicity of Refecoxib and Naproxen in Patients with Rheumatoid Arthritis, 343 NEW ENG. J. MED. 1520 (2000). (2006).

et al., Response to Expression of Concern Regarding VIGOR Study, 354 NEw ENG. J.MED. 1196

CURFMAN, Gregory, et al., Expression of Concern: Bombardier et al., "Comparison of Upper Gastrointestinal Toxicity of Rofecoxib and Naproxen in Patients with Rheumatoid Arthritis", 353 NEWENG. J.MED. 2813 (2005).

et al., Expression of Concern Reaffirmed, 354 NEW ENG.J. MED. 1193 (2006).

DEER, Brian. The Wakefield Factor, http://briandeer.com/wakefield-deer.htm (Mar. 24, 2010).

MMR Doctor Given Legal Aid Thousands, TIMESONLINE, Dez. 31, 2006, http://www.timesonline.co.uk/tol/news/uk/article1265373.ece.

EPSTEIN, Richard A. On Drafting Rules and Procedures for Academic Fraud, 24 MINERVA 344 (1986).

Dióxido de Carbono: Nosso Mais Novo Poluente, 43 SUFFOLKU. L. REv. (2010).

Overdose: how excessive regulation stifles pharmaceutical innovation 209-18 (2006);

Conflicts of Interest in Health Care: Who Guards the Guardians? 50 PERSP. IN BIOLOGY \& MED. 72, 84-88(2007).

GORSKI, David Gorski. Science-Based Medicine, disponível em http://www.sciencebasedmedicine.org/

HUGHES, Sue. Naproxen Best NSAID for Heart-DiseasePatients, HEARTWIRE, 28 de maio, 2009, http://www.theheart.org/article/974679.do.

HUNT, Morton.AFraud That Shook The World of Science, N.Y.TIMES MAG., Nov.1,1981, disponível em http://www.nytimes.com/1981/1 1/OI/magazinefa-fraud-that-shook-the- $\quad$ world-ofscience.html? \&pagewanted=print.

KRAUSKOPF, Lewis Krauskopf. Merck Agrees to Pay \$4.85 Billion in Vioxx Settlement, REUTERS, 9 de novembro, 2007, disponível em: http://www.reuters.con/article/idUSL0929726620071 110.

MARTIN JR, John S. Report to the Special Comm. of Merck \& Co.71-80 (2006), disponível em http://www.merck.com/newsroom/vioxx/martinreport.html.

REICIN, Alise; SHAPIRO, Deborah. Response to Expression of Concern Regarding VIGOR Study,354 NEW ENG.J. MED. 1196 (2006).

SHEPPARD, Marc. IPCC: International Pack of Climate Crooks, AMERICAN THINKER, Fev. 4, 2010, disponível em: http://www.americanthinker.com/2010/02/ipcc.-intemational-paci of_cli.html;

UNClimate Reports: They Lie, AMERICAN THINKER, Out. 5, 2009, disponível em: http://www.americanthinker.com/2009/10/un climate reports they lie.html. 
WALLIS, Claudia Wallis et al., Medicina: Fraude em Laboratório da Harvard, TIME, Fev. 28, 1983, disponível em http://www.time.com/time/magazinearticle/0,9171,955142,00.html.

WAKEFIELD, A. J. et al, Ileal-Lymphoid-Nodular Hyperplasia, Non-Specific Colitis, and Pervasive Developmental Disorder in Children, 351 LANCET 637 (1998).

\section{Documentos Públicos}

Climate Change Investigator Resigns over Interview Defending Researchers, TELEGRAPH, Fev. 12,2010, disponível em: http://www.telegraph.co.uk/earth/environiment/climatechange/7219070/Clinatechange-investigator-resigns-over-interview-defeding- researchers.html.

Editorial: Retraction-Ileal-Lymphoid-Nodular Hyperplasia, Non-Specific Colitis, and Pervasive Developmental Disorder in Children, 375 LANCET 455 (2010).

Int'l Comm. of Med. Journal Editors, Uniform Requirements for Manuscripts Submitted to Biomedical Journals, http://www.icmje.org/publishing.2corrections.html (último acesso, Mar. 24, 2010)

Lista de casos citados (por ordem de citação)

(1889) 14 App. Cas. 337, 375 (H.L.)

425 U.S. 185, 199 (1976).

Massachusetts v. EPA, 549 U.S. 497 (2007).

Ottmann v. Hanger Orthopedic Group, Inc., 353 F.3d 338 (4th Cir. 2003).

New York Times v. Sullivan, 376 U.S. 274 (1964).

Doe v. Ortho-Clinical Diagnostics, Inc., 440 F. Supp. 2 d 465 (M.D.N.C. 2006).

Pafford v. Sec'y of Health \&Human Servs., 451 F.3d 1352 (Fed. Cir. 2006)

Trabalho enviado em 29 de jultho de 2015

Aceito em 06 de setembro de 2015. 